Natur «gegenüber» steht, so wie der Mensch vor Kopernikus dem Universum gegenüber stand. Das ist gerade nicht die integrative Beziehung zu Natur und Kosmos. «Vielleicht können Menschen die natürlichen Verhältnisse weder endgültig beherrschen noch dauerhaft behüten», schrieb kürzlich der Philosoph Michael Hampe in der NZZ (20.8.2011). Er beklagt eine Ideologie, welche Natur und Vernunft entzweit habe und uns von der überwältigenden Wirklichkeit des Natürlichen trenne, so wie man auch einen Menschen nicht wirklich wahrnehme, wenn man ihn nur von den eigenen Bedürfnissen und Ängsten her betrachte. Man dürfe aber, weil ein Krisenbewusstsein sich zeige, «immerhin vermuten, dass die Rede von «der〉 Natur, die verbraucht werden kann oder geschützt werden muss, ihrem Ende entgegengeht. Welche Rede an ihre Stelle tritt, werden erst die wissen, die ein anderes Leben führen.» Hampe meint hier, wie Morin auch, einen Paradigmenwechsel, aber seine feinsinnige Sprache weiss, dass ein solcher nicht durch willentliche Beschlüsse herbeigeführt werden kann.

Damit ist, vielleicht, auch auf das Religiöse verwiesen. Die Idee, dass die Menschheit nur sich selber gegenüber verantwortlich sei, ist relativ neu, und in unseren Tiefen vernehmen wir immer noch ein leises Rufen ins Transzendentale. Im Rufen klingt die Frage mit, ob wir uns denn wirklich an den eigenen Haaren aus der Natur herausziehen können, ob unsere selbstbewusste Selbstverantwortung nicht gerade die Ursache dessen sei, das uns jetzt drohe, ob unser Aussenstandpunkt, der die Welt rationalisierbar und manipulierbar, und nun gar rettbar gemacht habe, nicht selbst unsere Hybris sei. Dann würde diese Hybris ihre Fortsetzung finden in der Idee, ein Gleichgewicht sei wieder herzustellen, und der Mensch dazu anzuleiten. Auf eine Vermessenheit türmte sich die nächste.

Die Freiheit steht zur Diskussion und die Frage, ob ihre Opferung zur Rettung unserer Lebensgrundlagen nicht ein weit zerstörerischeres Potential in sich trägt, als es im Wagnis der Freiheit schlummert. Falls der säkulare Mensch diese falsch verstanden hat und sie sich deshalb als eine Gefahr für unsere physikalischen Ressourcen herausstellt, dann möchten wir sie trotzdem nicht gegen die Diktatur der Ökologie eintauschen, sondern sie wieder in den Kontext von Werten stellen, die ihre Gewähr jenseits von unserer Verfügungsgewalt haben. Solches aber ist nicht durch Dekrete zu erreichen.

\title{
Sind wir zu dumm zum Überleben?
}

Peter Meyer

1 Martin J. «Der Soldat Erde muss gerettet werden». Schweiz Ärztezeitung. 2011;92(34):1302

Korrespondenz:

Dr. med. Peter Meyer Facharzt für Allgemeinmedizin FMH Birmensdorferstr. 393 CH-8055 Zürich

praxis-p.meyer@swissonline.ch
Liebe Redaktion, lieber Herr Kollege Martin Einmal mehr ein Statement für die Umwelt Ihrerseits [1], von den Ärzten hört man recht wenig in diesem überlebensnotwendigen Bereich. Gegen den numismatischen Wahnsinn wagen Sie sogar, das exponentielle Wachstum (wie Krebszellen) in Frage zu stellen - Chapeau. Interessant die Feststellung, dass Entwicklungshilfe Korruption schafft und Kriminalität fördert, sehr nachvollziehbar. Dann die sattsam bekannten Klagen über die verlorene Beziehung zur Natur, die Komplexität der Welt, das Wasserproblem, dass wir blind laufen, dass es einer Weltregierung bedürfe (was ist denn die UNO?) usw., jedenfalls keine echten Lösungsvorschläge - soll ich beginnen, Zoloft zu nehmen?

Einmal mehr möchte ich einen ganz zentralen, uns Ärzten sehr nahen Lösungsansatz vorschlagen, der alle, ich wiederhole, alle obgenannten Klagen einer sehr humanen Lösung zuführt: Fördern der Familienplanung, genau dort, wo sie am notwendigsten ist.

Unsere Welt erträgt weder die Konsummonster im Norden noch die 80000000 Menschen mehr jedes Jahr in der dritten Welt. Über die grausigen Migrationsströme beginnt genau dort das exponentielle Wachstum. Die UNO weiss von 200 Millionen Menschen in der dritten Welt, die familienplanen möchten, es aber nicht können, weil wir Dummköpfe es bisher versäumt haben, die Infrastruktur dafür dorthin zu bringen, wo sie so dringend erwünscht ist. Es resultieren allseits nur Win-win-Situationen. Gibt es einen grösseren Menschheitsskandal als jene 80 Mio. Babys, die schon von ihren Müttern unerwünscht sind?

Wie kann ein Ethiker diesen planetentötenden Wahnsinn derart konsequent verschweigen, gleichsam nur immer vom Ozean reden, ohne das Wort Salzwasser je zu gebrauchen? Warum schreiben die Ethiker dieser Welt nicht laut heraus, dass die Familienplanung (bei uns im Norden ein ganz selbstverständliches Menschenrecht, welches ursächlich Armut verhindert) die erste conditio sine qua non ist, warum reden wir immer um die Symptome der Überbevölkerung herum, statt diese selbst endlich mal ins Zentrum der Betrachtungen zu nehmen, hier kann man tatsächlich etwas tun.

In den dreissig Jahren, die Herr Morin die Weltprobleme beobachtete, um danach das Buch $\mathrm{zu}$ schreiben, hat die Weltbevölkerung von 4,44 Milliarden auf heute 7,87 Mia. Menschen zugenommen, also um 3,4 Mia. oder $+76 \%$. Wie kann man diese höllische Grundtatsache, die alle tausenden Folgesymptome verursacht, nur so teuflisch konsequent totschweigen? Was für ein weltzerstörender Wahnsinn steckt dahinter? Sind wir zu dumm zum Überleben? 